\title{
Rheumatoid arthritis, corticosteroid therapy and hip fracture*
}

\author{
C Cooper, C Coupland, M Mitchell
}

\begin{abstract}
Objective-To identify the risk of hip fracture in patients with rheumatoid arthritis and those taking corticosteroids. Methods-In a population based casecontrol study, we compared 300 consecutive patients with hip fracture aged 50 years and over from a defined district and 600 age and sex matched community controls.

Results-The risk of hip fracture was increased in patients with rheumatoid arthritis (odds ratio (OR) $2 \cdot 1 ; 95 \%$ confidence interval (CI) 1.0 to $4 \cdot 7$ ) and those receiving corticosteroids (OR 2.7; $95 \% \mathrm{CI} 1 \cdot 2$ to $5 \cdot 8)$. The risk attributable to rheumatoid arthritis was markedly reduced by adjusting for functional impairment, while that for steroid use remained after adjusting for body mass index, smoking, alcohol, and functional status.

Conclusions-Hip fracture risk is approximately doubled amongst patients with rheumatoid arthritis and among those taking steroids. These risk increases are, to some extent, independent of each other. In rheumatoid arthritis, the risk was most closely associated with functional impairment, whereas steroid use did not appear to be confounded by this variable.
\end{abstract}

(Ann Rheum Dis 1995; 54: 49-52)

The occurrence, skeletal distribution, clinical importance and cause of generalised osteoporosis in rheumatoid arthritis remains controversial. ${ }^{1-12}$ Several reports have suggested a tendency to bone loss throughout the skeleton in patients with the disorder, ${ }^{2}{ }^{36}$ but the sites at which loss is most pronounced remain uncertain. Other studies report that patients with rheumatoid arthritis have no reduction in axial bone density unless they are treated with corticosteroids. ${ }^{11} 12$ The major clinical consequence of any generalised reduction in bone density among such patients would be fracture, and hip fracture is the most dramatic of the fractures associated with osteoporosis. There are, however, few data on hip fracture risk among patients with rheumatoid arthritis. ${ }^{13} 14$ Furthermore, the relative contributions to the development of fractures made by corticosteroid therapy, functional impairment, or the rheumatoid disease process itself are unclear. In the only previous controlled study of the incidence of hip fracture in patients with rheumatoid arthritis ${ }^{13}$ the relative risk for hip fracture was significantly, but modestly, increased. If this increase in hip fracture risk could be confirmed, and its causes delineated, more effective strategies could be designed to retard age related bone loss in patients with rheumatoid arthritis. We have therefore examined the influence of rheumatoid arthritis on the risk of hip fracture in a population based case-control study.

\section{Patients and methods}

The case group comprised 300 patients (60 men and 240 women) aged 50 years and over who were admitted sequentially to an orthopaedic unit over an 18 month period with fracture of the proximal femur, ${ }^{15}$ and who were able to pass an abbreviated mental test. ${ }^{16}$ Patients in the study group were compared with 600 community controls, resident in the same district, who were selected from the register of Hampshire Family Practitioner Committee. Controls were matched to cases by sex and age within four years. The rate of response among controls was $71 \%$ of those contacted. When a control refused to participate or failed the mental test score a substitute was selected.

Each case-control set was visited by one of three trained interviewers. Cases were interviewed in hospital within 10 days of admission. Controls were interviewed at home within three months of their matched case $(68 \%)$ or during the corresponding quarter one year later $(32 \%)$.

At interview, information included a previous medical history. The patients who reported that they had previously been diagnosed by a physician as suffering from rheumatoid arthritis had their hospital or general practice records screened for documentation of the American Rheumatism Association (ARA) criteria. $^{17}$ Patients were defined as suffering from rheumatoid arthritis if they met the criteria for definite or classical disease or if deformity typical of the disorder was apparent. Hospital records were only available for the cases, and five were identified who reported rheumatoid arthritis, but in whom the diagnosis was not verified by record review. Although these individuals were classified as non-exposed for most of the analyses, the relationship between rheumatoid arthritis and hip fracture was also examined when these five subjects were included. Specific enquiry was also made as to current 
use of oral corticosteroids. Other potential risk factors recorded at interview included body weight and height, cigarette smoking and alcohol consumption. Dependence in daily living activities was assessed using the six point Katz index of activities of daily living. ${ }^{18}$ This ascertains the degree of independence in feeding, continence, transferring, going to the toilet, dressing and bathing. Increases in score from one to six indicate progressively worsening functional impairment.

Table 1 Sex distribution of study population and patients with rheumatoid arthritis or taking corticosteroids

\begin{tabular}{lrrrrr}
\hline & \multicolumn{2}{l}{ Cases } & & \multicolumn{2}{l}{ Controls } \\
\cline { 2 - 3 } \cline { 6 - 7 } \cline { 6 - 7 } & Male & Female & & Male & Female \\
\hline Number & 60 & 240 & & 120 & 480 \\
Rheumatoid arthritis & 1 & 13 & 2 & 12 \\
Corticosteroid use & 1 & 15 & & 1 & 12 \\
\hline
\end{tabular}

Table 2 Hip fracture risk in patients with rheumatoid arthritis and those taking corticosteroids

\begin{tabular}{|c|c|c|c|c|c|}
\hline \multirow[t]{2}{*}{ Risk factor } & \multirow[t]{2}{*}{ Sex } & \multicolumn{4}{|l|}{ Odds ratio } \\
\hline & & Unadjusted (95\% CI) & $p$ & Adjusted $^{\star}(95 \%$ CI) & $p$ \\
\hline Rheumatoid arthritis & $\begin{array}{l}\text { Men } \\
\text { Women } \\
\text { Both }\end{array}$ & $\begin{array}{l}1 \cdot 0(0.1 \text { to } 11.0) \\
2 \cdot 4(1.0 \text { to } 5 \cdot 4) \\
2 \cdot 1(1.0 \text { to } 4.7)\end{array}$ & $\begin{array}{l}1.00 \\
0.04 \\
0.06\end{array}$ & $\begin{array}{l}1.0(0.1 \text { to } 11.0) \\
2.1(0.9 \text { to } 5.0) \\
1.9(0.9 \text { to } 4.3)\end{array}$ & $\begin{array}{l}1.00 \\
0.09 \\
0.11\end{array}$ \\
\hline Corticosteroid use & $\begin{array}{l}\text { Men } \\
\text { Women } \\
\text { Both }\end{array}$ & $\begin{array}{l}2 \cdot 0(0.1 \text { to } 32 \cdot 0) \\
2 \cdot 8(1.2 \text { to } 6 \cdot 2) \\
2 \cdot 7(1 \cdot 2 \text { to } 5 \cdot 8)\end{array}$ & $\begin{array}{l}0.63 \\
0 \cdot 01 \\
0.01\end{array}$ & $\begin{array}{l}2 \cdot 0(0 \cdot 1 \text { to } 32 \cdot 0) \\
2 \cdot 5(1 \cdot 1 \text { to } 5 \cdot 8) \\
2 \cdot 5(1 \cdot 1 \text { to } 5 \cdot 5)\end{array}$ & $\begin{array}{l}0.63 \\
0.03 \\
0.02\end{array}$ \\
\hline
\end{tabular}

*Odds ratio for fracture from rheumatoid arthritis, after adjusting for steroid use (and vice versa) in a multiple logistic regression model. $\mathrm{CI}=$ Confidence interval.

Table 3 Body build, functional impairment, lifestyle, and the risk of hip fracture

\begin{tabular}{|c|c|c|c|c|c|c|}
\hline \multirow[t]{2}{*}{ Risk factor } & \multicolumn{2}{|c|}{ Category } & \multicolumn{2}{|c|}{ Number of } & \multicolumn{2}{|c|}{ Odds ratio $(95 \%$ CI) } \\
\hline & & & Cases & Controls & & \\
\hline $\begin{array}{l}\text { Body mass index } \\
\left(\mathrm{kg} / \mathrm{m}^{2}\right)\end{array}$ & \begin{tabular}{r}
\multicolumn{1}{c}{$M$} \\
$<20.4$ \\
20.4 \\
21.6 \\
23.2 \\
$>24.9$
\end{tabular} & $\begin{array}{r}\mathrm{F} \\
<19 \cdot 2 \\
19 \cdot 2 \\
21 \cdot 1 \\
22 \cdot 9 \\
>25 \cdot 6\end{array}$ & $\begin{array}{l}88 \\
67 \\
60 \\
40 \\
24\end{array}$ & $\begin{array}{r}84 \\
94 \\
112 \\
128 \\
144\end{array}$ & $\begin{array}{l}1 \cdot 0 \\
0 \cdot 6 \\
0.5 \\
0.3 \\
0 \cdot 2\end{array}$ & $\begin{array}{l}\overline{(0.4} \text { to } 1.0) \\
(0.3 \text { to } 0.8) \\
(0.2 \text { to } 0.5) \\
(0.1 \text { to } 0.3)\end{array}$ \\
\hline $\begin{array}{l}\text { Functional impairment } \\
\text { (Katz ADL score) }\end{array}$ & & $\begin{array}{l}1 \\
2 \\
3 \\
4+\end{array}$ & $\begin{array}{r}157 \\
77 \\
38 \\
28\end{array}$ & $\begin{array}{r}420 \\
124 \\
34 \\
21\end{array}$ & $\begin{array}{l}1 \cdot 0 \\
1 \cdot 9 \\
3 \cdot 4 \\
4 \cdot 4\end{array}$ & $\begin{array}{l}-\overline{(1.3} \text { to } 2 \cdot 8) \\
(2.0 \text { to } 5 \cdot 8) \\
(2 \cdot 3 \text { to } 8 \cdot 4)\end{array}$ \\
\hline Cigarette smoking & \multicolumn{2}{|c|}{ Ever $v$ never } & 145 & 223 & $1 \cdot 7$ & $(1 \cdot 2$ to $2 \cdot 3)$ \\
\hline Alcohol consumption & \multicolumn{2}{|c|}{$\begin{array}{l}\text { Occasional/abstainer } \\
\text { Light } \\
\text { Moderate/heavy }\end{array}$} & $\begin{array}{r}163 \\
108 \\
28\end{array}$ & $\begin{array}{r}328 \\
205 \\
12\end{array}$ & $\begin{array}{l}1 \cdot 0 \\
1 \cdot 3 \\
7 \cdot 5\end{array}$ & $\begin{array}{l}\overline{(1.0} \text { to } 1 \cdot 8) \\
(3 \cdot 3 \text { to } 16 \cdot 8)\end{array}$ \\
\hline
\end{tabular}

$\mathrm{CI}=$ Confidence interval .

Table 4 Hip fracture risk in patients with rheumatoid arthritis, after sequential adjustment for body mass index, cigarette smoking, alcohol consumption, and functional impairment

\begin{tabular}{llll}
\hline Risk factor & Other variables in model & Odds ratio (95\% CI) & $p$ \\
\hline Rheumatoid arthritis & None & $2 \cdot 1(1.0$ to $4 \cdot 7)$ & 0.06 \\
& BMI, smoking, alcohol & $1.9(0.8$ to $4 \cdot 8)$ & 0.12 \\
& BMI, smoking, alcohol, ADL & $1 \cdot 3(0.5$ to 3.5$)$ & 0.78 \\
\hline
\end{tabular}

$\mathrm{CI}=$ Confidence interval; $\mathrm{BMI}=$ body mass index; $\mathrm{ADL}=$ assessment of activities of daily living.

Table 5 Hip fracture risk in patients using corticosteroids after sequential adjustment for body mass index, cigarette smoking, alcohol consumption, and functional impairment

\begin{tabular}{llll}
\hline Risk factor & Other variables in model & Odds ratio (95\% CI) & $p$ \\
\hline Corticosteroid use & None & $2.7(1.2$ to $5 \cdot 8)$ & 0.01 \\
& BMI, smoking, alcohol & $2.5(1 \cdot 1$ to $5 \cdot 9)$ & 0.04 \\
& BMI, smoking, alcohol, ADL & $2 \cdot 1(0.9$ to $5 \cdot 2)$ & 0.06 \\
\hline
\end{tabular}

$\mathrm{CI}=$ Confidence interval $; \mathrm{BMI}=$ body mass index; $\mathrm{ADL}=$ assessment of activities of daily living.
Comparisons between cases and controls were by conditional logistic regression for matched sets. ${ }^{19}$ In case control studies, this analysis permits estimation of odds ratios as measures of association, which may be interpreted as relative risks.

\section{Results}

The ages of the cases ranged from 50 to 99 (median 79) years. To obtain the required 600 controls it was necessary to approach 889 subjects. The reasons for the incomplete response were death or change of address (73), failure of mental test (65), and refusal (151). Fourteen cases $(4 \cdot 7 \%)$ and 14 controls $(2 \cdot 3 \%)$ were identified who had rheumatoid arthritis (table 1); 25 of these $28(89 \%)$ were women. The mean age of cases with hip fracture was 79 (range 50-99) years, that of cases with rheumatoid arthritis was 76 (60-87) years, while that of arthritic controls was 77 (66-90) years. The overall prevalence of corticosteroid use in the study sample was $3 \cdot 2 \%$. Of the 29 individuals who were taking corticosteroids, 16 were cases and 13 were controls. In six of the 29 receiving steroids, rheumatoid arthritis was documented. In the remaining 23 , the major reasons for steroid use were chronic obstructive airways disease and polymyalgia rheumatica.

Table 2 shows that the unadjusted risk (odds ratio) of hip fracture in patients with rheumatoid arthritis was $2 \cdot 1$ (95\% confidence interval (CI) 1.0 to $4.7 ; \mathrm{p}=0.06$ ); that in subjects who were receiving steroids was $2 \cdot 7$ ( $95 \%$ CI 1.2 to $5 \cdot 8 ; p=0 \cdot 01)$. Table 2 also shows that when these risk estimates were mutually adjusted in a logistic regression model, it was apparent that the effects of rheumatoid arthritis and steroid use on hip fracture were, to a large extent, independent of each other. In a separate stratified analysis, those taking steroids but who did not have rheumatoid arthritis had a fracture risk of $2 \cdot 8$ (95\% CI 1.2 to $6 \cdot 5)$, while patients with rheumatoid arthritis who did not use steroids had an odds ratio for hip fracture of $2 \cdot 2(95 \%$ CI 0.9 to $5 \cdot 1$ ). There was little evidence for a multiplicative effect between steroid use and rheumatoid arthritis: the odds ratio in patients with both exposures was only $2.9(95 \%$ CI 0.6 to $15 \cdot 0$ ).

Table 3 shows the distribution among cases and controls of four other variables found to be significantly $(p<0.05)$ associated with fracture risk. Risk declined progressively with increasing body mass index and increased with increasing functional impairment. It was also increased by cigarette smoking and alcohol consumption. Tables 4 and 5 show the risk of hip fracture with rheumatoid arthritis and steroid use, after sequential adjustment for body mass index, cigarette smoking, alcohol consumption, and functional impairment. The excess risk attributable to steroid therapy appeared little changed by adjustment for these potentially confounding variables, while that for rheumatoid arthritis was markedly reduced by adjusting for functional impairment. These 
changes in odds ratio, however, did not attain statistical significance, perhaps because of the relatively low prevalence of both rheumatoid arthritis and steroid consumption in the study sample as a whole.

\section{Discussion}

The results of this study suggest that the risk of hip fracture is increased in patients with rheumatoid arthritis and in those who take corticosteroids. For both these exposures, the risk of hip fracture is approximately doubled, and the effects of each exposure appear to be largely independent of the other. Among patients with rheumatoid arthritis, the increased risk of hip fracture appears to be attributable predominantly to the functional impairment associated with the disease. However, the risk increase in those taking corticosteroids was little changed by adjusting for body mass index, cigarette smoking, alcohol consumption, and functional status.

Although many studies have examined changes in bone density among patients with rheumatoid arthritis, ${ }^{1-12}$ there have been relatively few controlled studies investigating the clinically more relevant end point of fracture. ${ }^{1314}$ In the only previous population based study to address specifically the issue of hip fracture risk in rheumatoid arthritis, 388 women from the northern United States who initially developed rheumatoid arthritis during the period 1950-74, were followed subsequently for 4902 person years. ${ }^{13}$ Twenty nine of them sustained hip fractures, and when this experience was compared with the expected incidence rate of hip fracture in that population, a relative risk of 1.5 was obtained. As with our own study, there was limited power to assess the contributions of various risk factors to this increase in risk, but a multivariate analysis suggested that ageing, impaired ambulation and thinness acted as independent risk factors. Although those receiving steroids had a greater risk of hip fracture (relative risk $=2 \cdot 15$ ) than others (relative risk $=1 \cdot 40$ ), these estimates were not significantly different. Given the differences in population samples and study design, these findings are very similar to our own. It is possible that, in our study, exclusion of subjects with dementia (a group likely to manifest a concentration of comorbidity) permitted better delineation of the independent contributions of rheumatoid arthritis and steroid use, to hip fracture risk. The excess of hip fracture in our study is also remarkably close to that observed for vertebral fracture in patients with rheumatoid arthritis. ${ }^{20}$

There are many difficulties in studying the association between disorders such as rheumatoid arthritis and fracture risk. When studies are population based, the prevalance of rheumatoid arthritis tends to be relatively low, and statistical power is correspondingly limited. Furthermore, there is no widely accepted method for the identification of those with rheumatoid arthritis in population studies. Through the use of a screening question enquiring about physician diagnosed rheumatoid arthritis, we are likely to have imposed a relatively specific but insensitive diagnostic threshold. ${ }^{21}$ The recording of ARA criteria in hospital and general practice case records, however, is likely to be incomplete, and hospital records were only available for the cases. When the additional five self reporting cases were included in the analysis, the odds ratio for rheumatoid arthritis increased from $2 \cdot 1$ to $2 \cdot 7$. The correspondence of these estimates with the previously performed North American retrospective cohort study ${ }^{13}$ supports their validity.

Rheumatoid arthritis is a systemic disease which results in joint inflammation and associated joint destruction. The release of cytokines by inflamed synovium mediates juxta-articular osteopenia which is most marked in the appendicular skeleton. ${ }^{7}$ Studies of axial bone density in patients with rheumatoid arthritis are rather less consistent. ${ }^{6-12}$ Some studies have reported that lumbar spine or femoral neck bone mineral density are reduced significantly in patients with rheumatoid arthritis who have not been treated with corticosteroids. ${ }^{6910}$ Others, however, have documented normal bone density values in women with the disorder. ${ }^{11}{ }^{12}$ In the only detailed study incorporating sufficient numbers of men, both steroid treated and nonsteroid treated men with rheumatoid arthritis had low femoral neck bone density values. ${ }^{10} \mathrm{An}$ increase in hip fracture risk among patients with rheumatoid arthritis might also be mediated through an increased risk of falling. Although cigarette smoking has not been clearly linked to falls in the elderly, functional impairment, heavy alcohol consumption, and low body mass have all been documented as risk factors for falling in epidemiological studies. ${ }^{22} 23$

Data on the influence of corticosteroids on bone density are numerous. ${ }^{24}$ There is consistent evidence that use of these agents is associated with a reduction in bone density, particularly in areas which contain a large proportion of trabecular bois. Remarkably, however, there are no published estimates from population based studies of the increase in hip fracture risk associated with steroid use. The median dose of prednisolone taken by the patients reporting steroid use in our study was $7.5 \mathrm{mg}$ daily. We were unable to obtain reliable estimates of the duration of use, or of previous use in individuals who were not current users. Our data suggest that steroid therapy is associated with a significant increase in hip fracture risk, and that this effect is independent of other risk factors for osteoporosis or falling. The independence of effects attributable to steroid use and rheumatoid arthritis is not surprising given the small number of cases in whom both factors were operating, and studies with greater statistical power are required to explore any potential interaction between these two exposures. The apparent independence of the two risk factors might also have resulted from the fact that current steroid use (rather than use ever) was ascertained. It is interesting, 
however, that steroid use in individuals with rheumatoid arthritis did not serve to increase markedly the overall risk of hip fracture. This influence of steroids on hip fracture risk in our study was in marked contrast to that previously reported on vertebral fracture risk. Spector et $a l^{20}$ examined the prevalence of vertebral deformities in 191 postmenopausal women with rheumatoid arthritis; five $(28 \%)$ of those with vertebral fractures had received steroids, compared with $46(35 \%)$ of those without fractures. Several case series, however, document prevalence rates of vertebral deformity which are considerably greater than expected among patients taking corticosteroids. $^{25-28}$

In conclusion, our data provide evidence that the risk of hip fracture is approximately doubled among patients who suffer from rheumatoid arthritis, and among those taking steroids. The risk increases attributable to each of these factors are, to some extent, independent of each other. In the case of rheumatoid arthritis, the major contributors to excess hip fracture risk appear to be thinness and functional impairment. Steroid use, however, does not appear to be confounded by these two variables. Clinicians should be aware of the association between rheumatoid arthritis, steroid therapy, and this most catastrophic outcome of bone loss. The investigation of measures to retard bone loss in the femoral neck should be evaluated urgently in patients with rheumatoid arthritis, to try and reduce the incidence of hip fracture.

We thank the consultants and staff of the department of orthopaedic surgery, Southampton General Hospital, and the orthopaedic surgery, Southampton General Hospital, and the
general practitioners of the Southampton health district. The manuscript was prepared by Mrs Gill Strange.

1 Saville P D, Kharmosh O. Osteoporosis of rheumatoid arthritis: influence of age, sex and corticosteroids. Arthritis arthritis: influence of age,

2 Kennedy A C, Smith D A, Anton H C, Buchanan W W Generalised and localised bone loss in patients with rheumatoid arthritis. Scand $\mathcal{f}$ Rheumatol 1975; 4 209-15.

3 Reid D M, Kennedy N S J, Smith M A, Tothill P, Nuki G Total body calcium in rheumatoid arthritis: Effect of disease activity and corticosteroid treatment. BMF 1982 285: $330-2$.

4 Als O S, Gotfredson A, Christiansen C. Relationship between local and total bone mineral in patients with rheumatoid arthritis and normal subjects. Clin Rheumatol 1983; 2: 265-71.

5 Als O S, Gotfredson A, Riis B J, Christiansen C. Are disease duration and degree of functional impairment determinants of bone loss in rheumatoid arthritis? Ann Rheum Dis 1985; 44: 406-11.
6 Sambrook P N, Eisman J A, Champion G D, Yeates M G, Pocock N A, Eberl S. Determinants of axial bone loss in rheumatoid arthritis. Arthritis Rheum 1987; 30: 721-8.

7 Cooper C, Poll V, McLaren M, Daunt S O M, Cawley M I D. Alterations in appendicular skeletal mass in patients with rheumatoid psoriatic and osteoarthropathy. Ann Rheum Dis 1988; 47: 481-4.

8 Butler R C, Davie M W J, Worsfold M, Sharp C A. Bone mineral content in patients with rheumatoid arthritis: relationship to low-dose steroid therapy. $\mathrm{Br} \mathcal{F}$ Rheumatol 1991; 30: 86-90.

9 Hall G M, Spector T D, Griffin A J, Jawad A S M, Hall M L, Doyle D V. The effect of rheumatoid arthritis and steroid therapy on bone density in post menopausal women. Arthritis Rheum 1993; 36: 1510-6.

10 Garton M J, Reid D M. Bone mineral density of the hip and of the antero-posterior and lateral dimensions of the spine in men with rheumatoid arthritis. Arthritis Rheum 1993; 36: $222-8$.

11 Verstraeten A, Dequeker J. Vertebral and peripheral bone mineral content and fracture incidence in post menopausal patients with rheumatoid arthritis. Ann Rheum Di 1986; 45: 852-7.

12 Compston J E, Crawley E O, Evans C, O'Sullivan M M Spinal trabecular bone mineral content in patients with non-steroid treated rheumatoid arthritis. Ann Rheum Dis 1986; 47: 660-4.

13 Hooyman J R, Melton L J, Nelson A M, O'Fallon W M, Riggs B L. Fractures after rheumatoid arthritis: a population-based study. Arthritis Rheum 1984; 27: population

14 Michel B A, Bloch D A, Wolf S, Fries J F. Fractures in rheumatoid arthritis: An evaluation of associated risk rheumatoid arthritis: An evaluation

15 Cooper C, Barker D J P, Wickham C. Physical activity, muscle strength and calcium intake in fracture of the proximal femur in Britain. $B M 7$ 1988; 297: 1443-6.

16 Quereshi K N, Hodkinson H N. Evaluation of a ten question mental test in the institutionalised elderly. $A g c$ Ageing 1974; 3: 152-7

17 Ropes M W, Bennett B A, Cobb S, et al. Revision of diagnostic criteria for rheumatoid arthritis. Bull Rheum Dis 1958; 9: 175-80.

18 Katz S, Ford A B, Moskowitz R W, Jackson B A Jaffe $M$ W. Studies of illness in the aged-the index of ADL; a standardised measure of biological and psychosocial functions. fAMA 1963; 185: 914-9.

psychosocial functions. $\mathcal{F} A M A$ 1963; 185: 914-9.
19 Breslow N E, Day N E. Conditional logistic regression from matched sets. In: Breslow $\mathrm{N} \mathrm{E}$, Day N E, eds. Statistical matched sets. In: Breslow N E, Day N E, eds. Statistical
methods in cancer research, vol 1 . The analysis of case control methods in cancer research, vol 1. The analysis of case control
studies. Lyon: International Agency for Research on studies. Lyon: Internatio
Cancer, 1980;248-79.

20 Spector T D, Hall G M, McCloskey E V, Kanis J A. Risk of vertebral fracture in women with rheumatoid arthritis. BMF 1993; 306: 558-9.

21 Star V L, Scott J, Sherwin R, Hochberg M C, Lane N, Nevitt N. Validity of self-reported physician diagnosed rheumatoid arthritis for use in epidemiologic studies [abstract]. Arthritis Rheum 1993; 9(suppl): S100.

22 Wickham C, Cooper C, Margetts B M, Barker D J P. Muscle strength, activity, housing and the risk of falls in elderly people. Age Ageing 1989; 18: 47-51.

23 Prudham D, Evans J G. Factors associated with falls in the elderly: a community study. Age Ageing 1981; 10: 141-6.

24 Adachi J D, Bensen W G, Hodsman A B. Corticosteroid induced osteoporosis. Semin Arthritis Rheum 1993; 22: 375-84

25 Curtiss P H, Clark W S, Herndon C H. Vertebral fractures resulting from prolonged cortisone and corticotropine therapy. FAMA 1954; 156: 467-9.

26 McConkey D, Fraser G M, Bligh A S. Osteoporosis and perpura in rheumatoid disease: Prevalence and relation to treatment with corticosteroids. $O \mathcal{F} \mathrm{Med} 1962 ; 31$ : 419-27.

27 Adinoff A D, Hollister J R. Steroid induced fractures and bone loss in patients with asthma. $N$ Engl f Med 1983; 309: 265-8.

28 Luengo $M$, Picado $C$, Delrio $L$ Guanabens $N$ Monserrat J M, Setoain J. Vertebral fractures in steroid dependent asthma and in volutional osteoporosis: comparative study. Thorax 1991; 46: 803-6. 